\title{
Na areia movediça
}

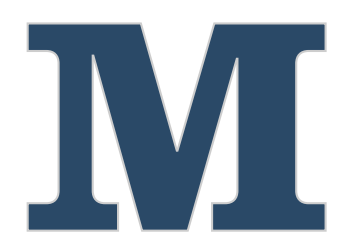

uitos profissionais de Recursos Humanos podem estar fundamentando suas práticas em princípios pouco consistentes, porém repetidos à exaustão e passados adiante como verdades inquestionáveis. 0 resultado pode ser danoso para as empresas e seus profissionais. Uma maior aproximação entre 0 mundo empresarial e a academia pode proporcionar as reflexões necessárias para garantir abordagens mais confiáveis.

por Maria JoséTonelli e Beatriz Maria Braga Lacombe FGV-EAESP

Na última década, virou lugar-comum afirmar que os indivíduos constituem o "ativo" mais importante das organizações. Fruto do espírito da época, surgiram dezenas de novas abordagens sobre gestão de pessoas, compreendendo desde teorias bem fundamentadas sobre alinhamento estratégico até propostas "pouco ortodoxas", envolvendo astrologia e numerologia.

Na prática, as mudanças nas políticas de RH não foram poucas, refletindo uma verdadeira avalanche de novidades. Algumas delas foram consistentes ebem solidificadas, outras nem tanto. Mas a falta de consistência não pareceter impedido sua popularização.

Foi esse quadro que motivou três pesquisadores da Universidade de lowa - Sara Rynes, Kenneth Brown e Amy Colbert - a questionarem algumas práticas de Recursos Humanos. Em um artigo publicado recentemente pela Human Resource M anagement, esses estudiosos mostram que muitas práticas, hoje consagradas, baseiam-se em fundamentos que não são confirmados por pesquisas científicas. 
Abismo explicado. 0 trabalho de Rynes, Brown e Col bert representa um alerta para os executivos de Recursos Humanos. Embora muitos profissionais da área procurem aperfeiçoamento em palestras e cursos de especialização, poucos efetivamente têm contato com os resultados de pesquisas científicas.

De fato, parece haver um abismo que separa os profissionais do mundo corporativo e os pesquisadores e membros da academia. É conveniente observar que existem motivos para esse distanciamento. 0 primeiro é o fato de que poucos diretores ou gerentes de Recursos Humanos têm o hábito de ler textos científicos. Por quê? Por um lado, porque essaliteratura se tornou demasiadamente especializada e técnica. Por outro, os profissionais não lêem porque acham a produção irrelevante, sem qualquer utilidade para suas necessidades.

O segundo motivo está na própria natureza do objeto: a gestão de pessoas. Embora se trate de uma área complexa, há uma impressão generalizada de que apenas o bom senso é suficiente para lidar com os problemas que aparecem. Mesmo que gerir pessoas signifique enfrentar uma grande diversidade de temas - como definição de políticas da organização do trabalho, compreensão dos aspectos comportamentais do corpo profissional, implementação de iniciativas de

\section{0 abismo que separa o mundo}

\section{corporativo da academia tem impedido}

\section{a união do dinamismo do primeiro com}

\section{a capacidade de reflexão do segundo.}

responsabilidade social da empresa e gerenciamento das relações com sindicatos e legislação trabal hista -, fica a idéia de que basta "gerenciar com bom senso". Assim, qualquer um seria capaz de atuar na área.

Todo esse contexto ajuda a tornar a esfera de gestão de pessoas um terreno fértil para 0 aparecimento e disseminação de mitos e crenças. Assim, várias práticas acabam sendo instituídas nas empresas sem que se faça uma verificação de sua aplicabilidade e de seus impactos potenciais. Não chega, portanto, a ser surpreendente que o estudo realizado pelos pesquisadores da Universidade de lowa tenha revelado que muitas das práticas de Recursos Humanos estão em absoluta contradição com as descobertas científicas.

0 foco de Rynes, Brown e Colbert foi investigar o quanto algumas premissas assumidas pelos profissionais de Recursos Humanos eram consistentes com resultados de pesquisas científicas realizadas naárea. 0 trabalho envolveu quase mil profissionais, com uma experiência média de 14 anos.

Mitos e fatos nas práticas em RH. Os pesquisadores encontraram dissonâncias em diversas áreas relacionadas à gestão de pessoas. Destacamos, abaixo, três dos mitos mais surpreendentes.

O mito da inteligência emocional. 0 primeiro mito relaciona-se às características dos funcionários: "ter funcionários comprometidos e dedicados é mais importante que ter funcionários simplesmente inteligentes". Por isso, os processos seletivos devem val orizar os candidatos com maior potencial de comprometimento e dedicação, conferindo mais peso a essa qualidade que à inteligência.

Ainda que $72 \%$ dos gerentes tenham concordado com essa afirmação, as pesquisas mais recentes têm demonstrado que testes de inteligência apresentam maior valor para previsão do desempenho do que características comportamentais como dedicação e comprometimento.

Qual a explicação para que os gerentes mantenham essa crença, a despeito das evidências científicas? Trata-se, em primeiro lugar, do espírito da época: depois do lançamento do livro de Daniel Goleman, Inteligência emocional, em 1990, a intel igência propriamente dita foi posta de lado e foi dada maior ênfase ao comportamento nos processos de recrutamento, treinamento e avaliação dos funcionários. Além disso, na opinião dos autores, existem fortes estereótipos em relação às pessoas inteligentes: elas são brilhantes, mas não são práticas; são capazes, mas são socialmente inaptas; são criativas, mas em alguns momentos fogem da realidade. Para completar, pessoas inteligentes costumam ser arrogantes e difíceis de gerenciar. 
Porém, do ponto de vista do conhecimento científico, não há qualquer correlação evidente entreinteligência e traços de personalidade: pessoas podem ser brilhantes e introvertidas; briIhantes e extrovertidas; brilhantes e neuróticas; brilhantes e emocionalmente estáveis.

E é claro que tanto a inteligência como a capacidade de uma pessoa ser comprometida e dedicada constituem fatores importantes a serem considerados nos processos de seleção de pessoal; eles não estão em oposição.

O mito das decisões participativas. 0 segundo mito determina que o melhor desempenho organizacional é geralmente obtido quando os funcionários são encorajad os a participar do processo decisório e não quando se estabelecem objetivos e metas para eles.

Essa parece ser uma das crenças mais freqüentes entre os profissionais, uma vez que apenas 17\% dos participantes da pesquisa discordaram da afirmação. No entanto, as evidências científicas mostram claramentequea afirmação não é totalmente verdadeira: segundo alguns estudos, o desempenho pode melhorar em $16 \%$ quando se estabelecem políticas de objetivos e metas e menos de $1 \%$ com políticas de participação em tomada de decisão.

Embora esses resultados possam surpreender, dadas as inúmeras histórias de sucesso que contam com processos decisórios participativos - como a Southwest Airlines nos Estados Unidos e a Semco no Brasil - , as pesquisas científicas deixam claro que o estilo participativo só gerará bons resultados quando se estabelece com rigor onde se quer chegar e o que se pretende com a participação.

Deixam claro, igualmente, que políticas e práticas não podem ser implementadas de maneira improvisada. 0 processo participativo na tomada de decisão ébom? Com certeza! Mas depende de uma série de outros fatores: dos objetivos e da postura dos líderes da organização, do processo de comunicação entre as pessoas, do fluxo da informação e do grau de complexidade e de abrangência da decisão a ser tomada. Não é preciso recorrer, por exemplo, a um processo

decisório participativo para se resolver problemas rotineiros como a escolha do fornecedor do vale-refeição!

O mito da remuneração. 0 terceiro mito consiste em afirmar que, nas pesquisas internas sobre remuneração, os funcionários tendem a supervalorizar a importância da remuneração em relação a outras formas de recompensa.

Embora 56\% dos participantes tenham concordado com a afirmação - de que as pessoas superestimam a importância da remuneração - , resultados de pesquisas científicas sugerem que essa suposição pode não se confirmar em todas as situações.

0 fato é que os resultados são diferentes quando se utilizam diferentes técnicas de pesquisa - questionamento direto ou indireto. Verificou-se que, quando perguntadas direta- 
mente sobre a importância das diversas formas de recompensa, as pessoas tendem a subvalorizar a importância do pagamento, eisso acontece porquenão pareceser socialmente correto admitir que o dinheiro é uma fonte de motivação para o trabalho.

No entanto, dois tipos de estudos que utilizam métodos indiretos mostram resultados bastante diferentes. No primeiro, pede-se que as pessoas comparem diversos cargos. Quando solicitadas a escolher entre eles, o critério "remuneração" aparece como muito importante, ao lado de prestígio, poder, status e outros. No segundo, pergunta-se quão importante é a remuneração para "pessoas como você"; nesse caso, observou-se que as pessoas tendem a ver o pagamento como 0 item mais importante da remuneração para todos, menos para si próprias.

Essas constatações reforçam que questões como a remuneração não são simples como tem sido divulgado e que, portanto, não podem ser resolvidas com fórmulas prontas. Os pesquisadores alertam que é preciso tomar muito cuidado com os resultados que se obtêm de pesquisas internas sobre remuneração e que é preciso observar, principalmente, a forma como esses dados foram colhidos. De outra maneira, corre-se o risco de criar políticas de RH insatisfatórias e ineficientes.

Críticas às práticas. Esses três mitos - para citar apenas al guns dos identificados pela pesquisa - exemplificam como as práticas de Recursos Humanos podem estar distantes de descobertas relevantes.

Embora muitas razões possam ser listadas para justificar que os resultados das pesquisas acadêmicas não sejam implementados nas organizações, o principal motivo parece ser a falta de conhecimento: os autores encontraram diferenças significativas nas respostas dos profissionais de Recursos Humanos que declararam ler eaqueles que não lêem as revistas científicas - 75\% afirmaram que nunca lêem tais publicações!

É possível argumentar que os executivos, pressionados pela necessidade de resultados rápidos, nem sempre têm tempo para se aproximar da literatura gerada na academia. Porém, podemos também sugerir que um certo viés antiintelectual cerca o mundo corporativo. 0 florescimento de uma vasta literatura de auto-ajuda reforça essa tese. A preferência dos executivos recai sobre textos rápidos que, de modo geral, não têm consistência nem apresentam evidências empíricas. Além disso, são raras as pesquisas que verificam os resultados obtidos com a implementação de práticas baseadas na literatura de auto-ajuda, como se essa vertente editorial não precisasse de comprovação ou validação.

Adicionalmente, a mídia de negócios tem divulgado conceitos e práticas que, ao serem implantados em contextos diferentes dos originais, sem uma reflexão crítica, podem levar a resultados inesperados e até provocar desastres.

A existência de modismos e a qualidade duvidosa dos "best-sellers de aeroporto" já foram questionadas inúmeras vezes em pesquisas nacionais e internacionais. Em Os bruxos da administração, por exemplo, John Micklethwait e Adrian Wooldridge, dois jornalistas, mostraram como se propagam as idéias dos gurus gerenciais, sem que haja qualquer teste de consistência do conhecimento transmitido.

Contexto local. E no Brasil? Os profissionais em Recursos Humanos do país conhecem e utilizam as pesquisas acadêmicas da área de administração? A resposta a essa pergunta parece ser, como no trabalho norte-americano, negativa.

Em uma pesquisa realizada em 1999 pelas autoras deste texto em cem empresas da Grande São Paulo, notou-se que muitos profissionais da área diziam considerar importante implantar o conceito de "RH Estratégico" - afinal, "todo mundo está fazendo isso!", alguns declararam. No entanto, esses profissionais tinham grandedificuldadeem definir exatamente do que estavam falando - o sentido do conceito.

Significativamente, muitos programas de mudança que estavam sendo conduzidos caracterizavam-se pelo uso mais ou menos livre de conceitos e metodologias, sem necessariamente haver correspondência entre o rótulo e a prática.

Alguns exemplos:

- Algumas empresas estavam implementando o sofisticado conceito deremuneração com base em habilidades e competências, mas ainda mantinham, e usavam como base, as antigas descrições de cargos, incompatíveis com o novo modelo. - Um número representativo de empresas estava investindo em desenvolvimento de pessoas, porém poucas haviam alinhado tais iniciativas às necessidades estratégicas eàs perspectivas de movimentação de pessoal. 
De forma geral, o discurso parece ter se adiantado - e descolado - bastante em relação à prática: a pesquisa local também constatou a utilização freqüente do "moderno" jargão de Recursos Humanos, com termos densos como diversidade, competências, responsabilidade social, parceria estratégica, empowerment, coaching e mentoring; porém, os conceitos praticados raramente correspondiam às definições dos termos, encontradas nos livros.

Papel indefinido. Diversas outras pesquisas confirmam que, no Brasil, a missão da área de Recursos Humanos não está clara para a maioria das empresas e o gestor de RH vê-se em uma posição na qual os parâmetros para sua ação não estão bem definidos. Com isso, a gestão de pessoas parece tender a se apoiar na intuição e no conhecimento superficial de al gumas técnicas e modelos de aplicação rápida e não em conceitos elaborados a partir da reflexão, que tenham como base os resultados de pesquisas científicas.

Deforma complementar, não podemos esquecer a fascinação que o estrangeiro exerce sobre nós brasileiros, fascinação que parece se repetir no consumo da literatura de negócios. Ora, grande parte dos conceitos e idéias trazidas por esses livros e artigos, além de apresentar consistência duvidosa, não pode ser aplicada de maneira irrefletida às nossas empresas, pois foi gera da em contextos institucionais, culturais e empresariais diferentes do nosso.

Reconciliação possível. Por outro lado, o mundo acadêmico também merece "reparos". Se há um viés antiintelectual e falta de conhecimento sobre a produção acadêmica por parte dos profissionais que atuam nas empresas, esta mesma produção também não se apresenta como alternativa à literatura de autoajuda empresarial.

De modo geral, a produção acadêmica brasileira em administração traz resultados irrelevantes, e muitos pesquisadores cultivam perigosa distância da prática empresarial. Com essa postura, tornam-se incapazes de enten der os problemas empresariais e definir agendas substantivas de pesquisa.
Alem disso, vários estudos quantitativos e qualitativos, além de restritos em escopo, apresentam graves limitações. De fato, é possível encontrar em revistas acadêmicas locais pesquisas extremamente frágeis, tanto em sua sustentação teórica e metodológica como em sua aplicabilidade prática.

Se nem tudo o queé produzido na academia tem valor e nem tudo o que ocorreno mundo corporativo merece aplausos, resta então a questão fundamental: como aproximar os dois universos, com suas forças e fraquezas, de forma a gerar complementaridade e criar condições para o avanço do conhecimento e da prática gerencial?

Embora não existam caminhos únicos de aproximação, a criação de fóruns conjuntos de debates e o desenvolvimento de projetos de pesquisa aplicada em parceria com empresas constituem rotas preferenciais.

É claro que os profissionais de Recursos Humanos, assim como aqueles das demais áreas da Administração, só teriam a ganhar com essa aproximação. A pesar das fraquezas apontadas, a pesquisa acadêmica pode discutir temas importantes - o comprometimento, a qualificação, a qualidade de vida no trabalho, os processos de mudança organizacional e seu impacto nas pessoas, entre tantos outros - que precisam ser compreendidos e trabalhados nas empresas.

\section{consomem avidamente textos superficiais.}

situação: muitos executivos de RH

Os pesquisadores, por sua vez, seriam beneficiados pela maior proximidade com a realidade organizacional e seu dinamismo. Ainda quenem toda pesquisa tenha aplicabilidade imediata, ela tem sempre o potencial de revelar a empresa para si mesma, proporcionando a reflexão crítica necessária para a superação de dificuldades, o aproveitamento efetivo de oportunidades e a contínua reinvenção das organizações. 